\title{
Maritimes Health Libraries Association (MHLA) / Association des Bibliothéques de la Santé des Maritimes (ABSM)
}

September and October, 2012, were busy and engaging months for MHLA/ABSM. For the first time, the Chapter participated in Associations Day at the Dalhousie School of Information Management (SIM), where we interacted with the students and signed up 13 new members. In October, long-time member Patrick Ellis was awarded the Outstanding Alumni Award by Dalhousie SIM.

October also saw the fall meeting of MHLA/ABSM in Halifax, hosted by the Izaak Walton Killam Health Centre. Scope of Practice conversations continued with a focused discussion on professional competencies for librarians and library assistants. This work is part of MHLA/ ABSM's strategic planning process and will be compiled and incorporated into a draft Scope of Practice document MHLA/ABSM will share with the general membership in the spring. The night before our meeting, MHLA/ABSM hosted a short one-hour presentation for Dalhousie SIM students and the wider library community in Halifax on Health Librarianship. It was felt to be a small but successful inaugural event. After the meeting, Joanne
Hodder gave an outstanding Continuing Education session on marketing. Ms. Hodder is a faculty member in the Library and Information Technology program at the Waterfront Campus of the Nova Scotia Community College. She focused on the benefits of marketing associations as a whole over individual libraries; the session was both inspiring and productive. The afternoon also yielded a new mission statement: "Supporting Health through Knowledge", which MHLA/ABSM will officially adopt in April at our spring meeting in Moncton.

\section{Michelle Helliwell, MLIS}

President, MHLA 2012-2014

Library \& Knowledge Management Services

Shared Services (Dalhousie School of Nursing - Yarmouth Site, Annapolis Valley Health, South Shore Health, South West Health)

23 Earnscliffe Ave. Wolfville, NS B4P $1 X 4$

E-mail:mhelliwell@avdha.nshealth.ca 